\title{
Reliability of the MPPT Control on the Energy Parameters of a Photovoltaic Generator
}

\author{
Batassou Guilzia Jeannot ${ }^{1}$, Mandeng Jean Jacques², Mane Mane Jeannot ${ }^{1}$ \\ ${ }^{1}$ Laboratory of Computer and Automatic Engineering, UFD of Engineering Sciences, ENSET, University of Douala, Douala, Cameroon \\ ${ }^{2}$ University Institute of Technology, UIT, University of Douala, Douala, Cameroon \\ Email: batassoujeannot@yahoo.fr,pheps1112@yahoo.fr, jeannotmane@yahoo.fr
}

How to cite this paper: Jeannot, B.G., Jacques, M.J. and Jeannot, M.M. (2020) Reliability of the MPPT Control on the Energy Parameters of a Photovoltaic Generator. World Journal of Engineering and Technology, 8, 537-550.

https://doi.org/10.4236/wjet.2020.83038

Received: July 29, 2020

Accepted: August 28, 2020

Published: August 31, 2020

Copyright (อ 2020 by author(s) and Scientific Research Publishing Inc. This work is licensed under the Creative Commons Attribution International License (CC BY 4.0).

http://creativecommons.org/licenses/by/4.0/

\begin{abstract}
This article describes a technique that allows a photovoltaic (PV) production unit to obtain the maximum power at all times. Here, we use the MPPT control via fuzzy logic on a DC/DC boost-type converter. In order to achieve our goals, we first proceeded to model a PV panel. The resulting model offers the possibility to better account for the influence of different physical quantities such as temperature, irradiation, series resistance, shunt resistance and diode saturation current. Thus, the maximum power to be provided by the PV system is acquired by fuzzification and defuzzification of the input and output variables of the converter. Subsequently, a virtual model of an $800 \mathrm{Watt}$ PV prototype is implemented in the Matlab environment. The simulation results obtained and presented, show the feasibility and efficiency of the proposed technology. Indeed, for a disturbance caused by a variation in brightness, our system guarantees the maximum stable power after $1.4 \mathrm{~s}$. While for a load variation, the maximum power is continuous.
\end{abstract}

\section{Keywords}

Low Voltage, Photovoltaic System, Fuzzy Logic, Maximum Power Point

\section{Introduction}

The incident of 04 November 2006 where Europe was plunged into darkness for an hour, the worst of the general Black-Out, pushed energy suppliers to opt for the integration of decentralized production into low-voltage electricity networks. However, the development of this decentralized production and the liberalization of the electricity market led to many new scientific and technical problems [1]. These problems relate to the geographical structure and management of these modern networks, but they also relate to the optimization of the supply of photovoltaic energy. Several methods have been used to operate the photovoltaic 
generator (PVG) at its maximum power point (MPP). Among these Maximum Point Power Tracking (MPPT) methods, the P \& O Method is essentially a trial and error method [2] [3]. This method does not allow the controller to reach its maximum point because of the slowness of the process and the variation in sunlight. On the other hand, the open and short-circuit method [4] has a fast response but cannot always provide the maximum power available due to photovoltaic (PV) characteristics and non-linear atmospheric conditions. Finally, while the Incremental Conductance Algorithm method [5] enables us to find the derivative of the power output of PV, the use of the derived algorithm makes this method unstable. However, Fuzzy Logic Control (FLC) which works like a black box model [6] [7] has advantages. It works with imprecise inputs and does not require a precise mathematical model. Moreover, it also handles the non-linearity problem [8] [9]. In 2016, Chafiaa Serir et al. [10] used fuzzy logic control to monitor and optimize the multi-source pumping system with the storage battery. Their work focused on system stability to protect the battery from overcharging and deep discharge. Several works have been conducted on this method but in 2019 Belgacem Mbarki et al. [11] did a comparative study on Maximum Power Point Tracking algorithms. Their work was more limited to the ranking of methods used for the determination of the maximum operating point. More recently in 2020 AfshabIlyas et al. [12] worked on the Real-time Implementation of an FPGA-based Fuzzy Logic Controller for Monitoring the Maximum Power Point of the Photovoltaic Solar System.

The aim of this work is to increase the reliability of the MPPT control over the PV parameters. In this paper, the fuzzy logic method will be used to control the inverter in order to always obtain the maximum power. The remaining sections of the article are organized as follows: In section 2, we describe the method and the materials used. Section 3 is devoted to the results, discussions and comments. Then follows the conclusion.

\section{Materials and Methods}

\subsection{Materials}

The structure of our photovoltaic system controlled by the MPPT controller is shown in Figure 1. It is mainly the photovoltaic modules, DC/DC converter, MPPT controller and load.

\subsubsection{Photovoltaic System Modeling}

The photovoltaic module represented by its equivalent electrical diagram given in Figure 2, consists of a current source modeling the luminous flux, losses modeled by two resistors, the shunt resistance $R_{s h}$, the series resistance $R_{S}$. In the end, appears in this diagram, the diode for the polarization of the cell and the phenomenon of recombination of minority carriers [13] [14].

The mathematical expressions describing the current-voltage characteristics for different environmental conditions: temperature and irradiation are developed as follows [15]: 


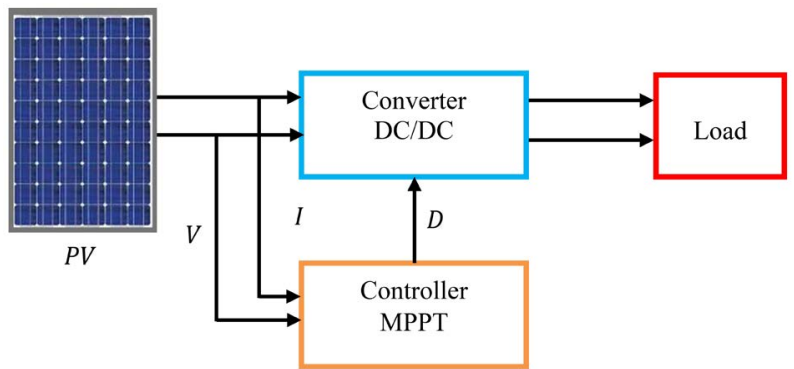

Figure 1. Photovoltaic conversion chain.

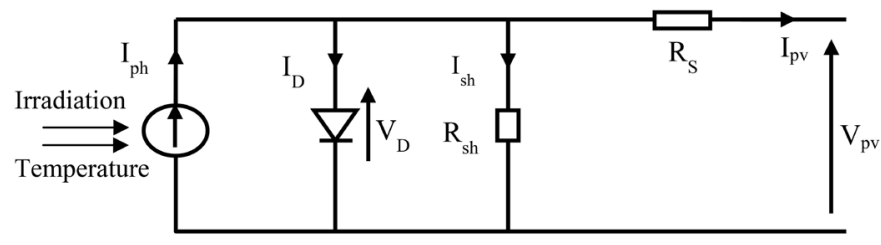

Figure 2. Equivalent electrical diagram of the one-diode model of the solar cell.

$$
I_{p v}+I_{D}+I_{s h}=I_{p h}
$$

Or $V_{D}=R_{s h} I_{s h} \Rightarrow I_{s h}=\frac{V_{p v}+R_{S} I_{p v}}{R_{s h}}$ with

$$
V_{D}=V_{p v}+R_{S} I_{p v}
$$

and

$$
\begin{gathered}
I_{D}=I_{0}\left(\exp \left(\frac{q}{n K T}\left(V_{p v}+R_{S} I_{p v}\right)\right)-1\right) \\
I_{p v}=I_{p h}-I_{0}\left(\exp \left(\frac{q}{n K T}\left(V_{p v}+R_{S} I_{p v}\right)\right)-1\right)-\frac{V_{p v}+R_{S} I_{p v}}{R_{s h}}
\end{gathered}
$$

By asking $W(x) \exp (W(x))=x \quad[16]$ we have:

$$
I_{p v}=\frac{I_{p h}+I_{0}-\frac{V_{p v}}{R_{s h}}}{1+\frac{R_{S}}{R_{s h}}}-\frac{n V_{T h}}{R_{S}} W\left[\frac{I_{0} R_{S}}{n V_{T h}\left(1+\frac{R_{S}}{R_{s h}}\right)} \exp \left(\frac{V_{p v}+\left(I_{p h}+I_{0}\right) R_{S}}{n V_{T h}\left(1+\frac{R_{S}}{R_{s h}}\right)}\right)\right]
$$

with $V_{T h}=\frac{K T}{q}$.

On the other hand, the expressions for the photon current, the energy supplied by a cell, and the cell resistances as a function of the temperatures and the effective and standard irradiation are developed by the following equations:

$$
\begin{gathered}
I_{p h}=\left[I_{s c}+K_{i}\left(T-T_{0}\right)\right] \frac{G}{G_{0}} \\
I_{0}=\frac{I_{p h}}{\exp \left(\frac{V_{o c}}{N}-1\right)}=\frac{\left[I_{s c}+K_{i}\left(T-T_{0}\right)\right] \frac{G}{G_{0}}}{\exp \left(\frac{q\left(V_{o c}+K_{v}\left(T-T_{0}\right)\right)}{a K T N_{s}}\right)-1}
\end{gathered}
$$




$$
I_{s}=I_{0}\left(\frac{T}{T_{0}}\right)^{3} \exp \left[\frac{q E_{g}}{n K}\left(\frac{1}{T}-\frac{1}{T_{0}}\right)\right]
$$

To obtain the maximum power, the current and the voltage should have their maximum values.

$$
P_{\max , m}=V_{m p} I_{m p}
$$

Using Equation (4) for the maximum value of the current, Equation (9) becomes:

$$
P_{\text {max }, m}=V_{m p}\left[I_{p h}-I_{0}\left(\exp \left(\frac{q}{n K T}\left(V_{m p}+R_{S} I_{m p}\right)\right)-1\right)-\frac{V_{m p}+R_{S} I_{m p}}{R_{s h}}\right]
$$

Or

$I_{p v}:$ Photovoltaic current (A);

$I_{s c}:$ Short-circuit current (A);

$I_{p h}$ : Light generated current (A);

$K_{i}: I_{s c}$ coefficient of temperature $\left(\mathrm{A} /{ }^{\circ} \mathrm{C}\right)$;

$K_{r}: V_{o c}$ coefficient of temperature $\left(\mathrm{V} /{ }^{\circ} \mathrm{C}\right)$;

$E_{g}$ : Gap energy (1.2 eV for crystalline silicon);

$G_{0}$ : Standard lighting $\left(1000 \mathrm{~W} / \mathrm{m}^{2}\right)$;

$I_{0}$ : Saturation current of the diode $(\mathrm{A})$;

$K$ : Boltzmann constant $\left(1.381 \times 10^{-23} \mathrm{~J} / \mathrm{K}\right)$;

$R_{S}$ : Series resistance $(\Omega)$;

$R_{s h}$ : Parallel resistance $(\Omega)$;

T: Effective cell temperature in kelvin (K);

$T_{0}$ : Standard temperature $\left(1000 \mathrm{~W} / \mathrm{m}^{2}\right)$.

Consequently, the physical behavior of the photovoltaic module is related to $I_{p h}, I_{0}, R_{S}$ and $R_{s h}$ on the one hand, and on the other hand with two other environmental parameters namely temperature and solar irradiation [17] [18].

\subsubsection{DC/DC Converter}

The Boost converter is the most suitable for the PV system, because it has a simple structure and a higher voltage gain than other converters for a given duty cycle [19]. For this reason, we are going to use in our system a step-up chopper which allows to operate the PV generator in such a way as to constantly produce the maximum of its power (Figure 3 ).

This converter is governed by the following equations:

$$
\begin{gathered}
v_{0}=\frac{1}{1-D} v_{p v} \\
i_{p v}=\frac{1}{1-D} i_{0} \\
i_{L}=i_{p v}-c_{1} \frac{\mathrm{d} v_{p v}}{\mathrm{~d} t} \\
i_{0}=(1-d) i_{L}-c_{2} \frac{\mathrm{d} v_{0}}{\mathrm{~d} t}
\end{gathered}
$$




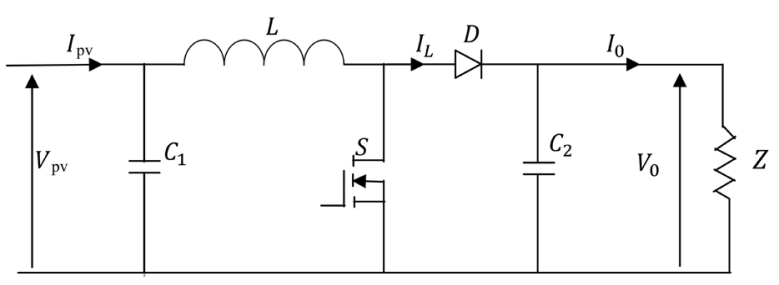

Figure 3. Boost mounting.

where $v_{0}$ and $i_{0}$ represent respectively the duty cycle, the output voltage and the current of the Boost converter.

In addition, we will optimize the DC/DC converters used as the interface between the PV generator and the load. This converter allows us to extract the maximum power and to operate this generator at its maximum power point using an MPPT (Maxumun Power Point tracking) controller. As it increases power, the power changes as well as the voltage. These variations are translated by the following equations:

$$
\begin{aligned}
\Delta P_{p v} & =P_{p v}(k)-P_{p v}(k-1) \\
\Delta V_{p v} & =V_{p v}(k)-V_{p v}(k-1)
\end{aligned}
$$

$P_{p v}(k)$ and $V_{p v}(k)$ are respectively the power and the voltage of the photovoltaic generator at an instant $k$.

\subsubsection{Maximum Power Point Tracking}

\section{1) Influence of illumination}

Here we evaluate in Matlab Simulink, the influence of sunlight on the PV system. The model equivalent to a diode of the photovoltaic cell shown in Figure 2 allowed us to obtain Equation (6) of the current photo. Based on this equation, the model of Figure 4 is obtained and the simulation results are shown in Figure 5 and Figure 6.

Figure 5 and Figure 6 show the current-voltage (I-V) and power-voltage (P-V) curves for different illuminances. The simulation results obtained show that the current photo depends on the solar irradiation. However, as the illuminance increases the current increases while the voltage increases slightly and therefore the power increases.

\section{2) Influence of temperature}

As the temperature varies according to time and period, we set the interval range $\left[0^{\circ} \mathrm{C}-100^{\circ} \mathrm{C}\right]$. The model in Figure 7 is obtained from Equations (7) and (4), and the simulation results are shown in Figure 8 and Figure 9.

For standard illuminance $\left(E=1 \mathrm{~kW} / \mathrm{m}^{2}\right)$. It can be seen from Figure 8 and Figure 9 that as the temperature rises, the open circuit voltage $V_{c o}$ decreases while the short-circuit current $I_{c c}$ is relatively constant and therefore the power decreases.

We notice that the no-load voltage of a module decreases with increasing module temperature while the short-circuit current increases slightly. Thus, the increase in temperature has a negative influence on the power as it decreases. At 
a constant temperature, the value of the short-circuit current is directly proportional to the radiation intensity. In contrast, the open-circuit voltage does not vary in the same proportion, but remains almost identical. This means that the power of the module is practically proportional to the illuminance. Thus, the power points are at approximately the same voltage.

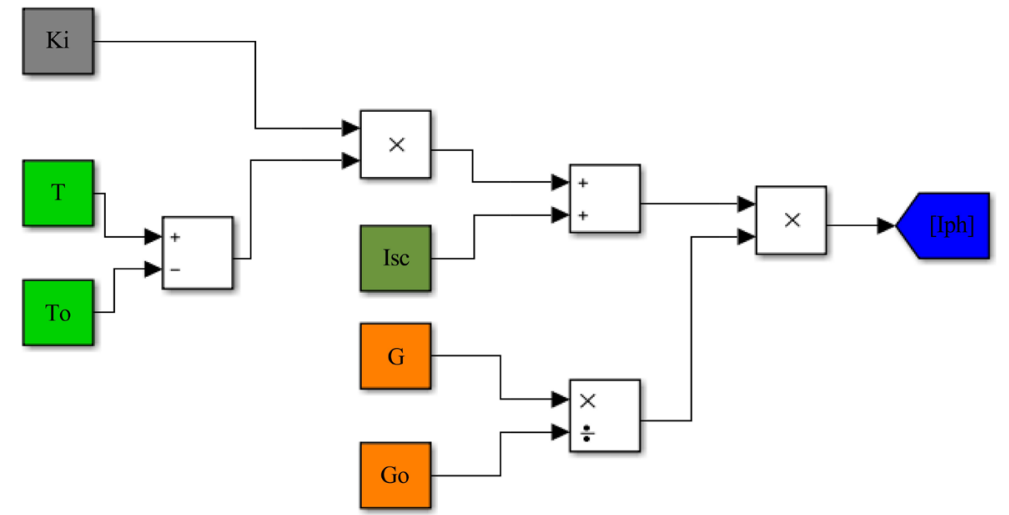

Figure 4. Calculation of $I_{p h}$ current.

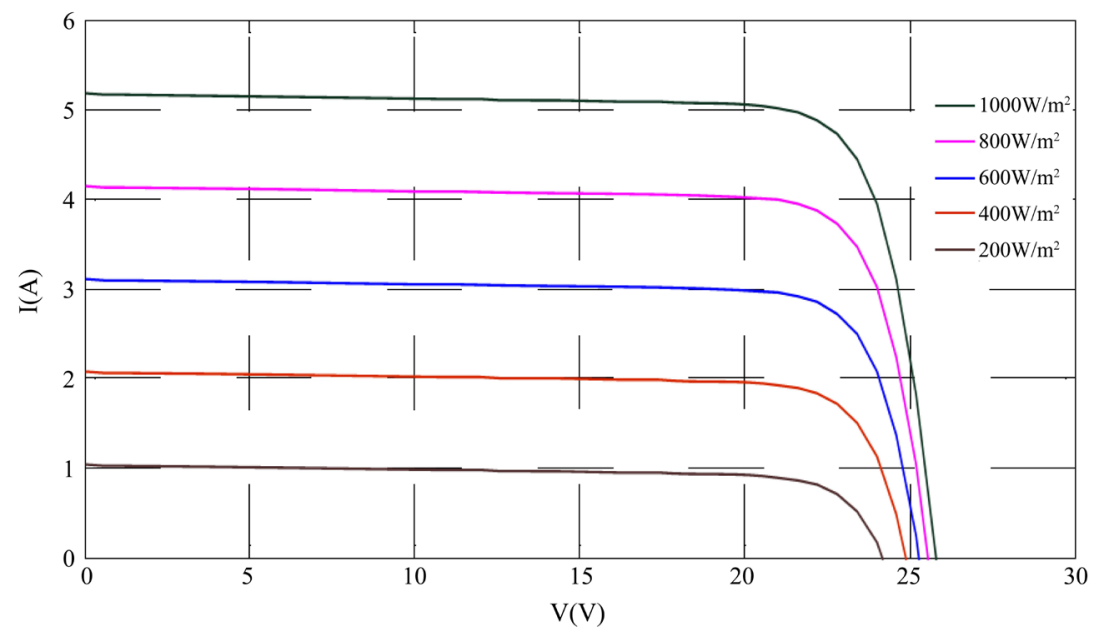

Figure 5. Characteristic I-V for different radiation values at $T=25^{\circ} \mathrm{C}$.

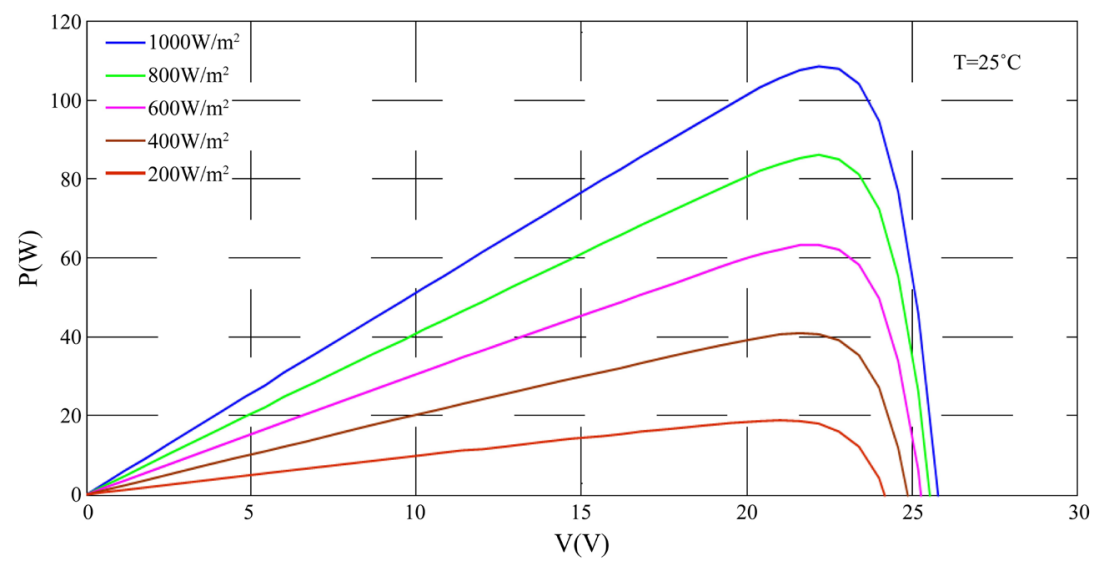

Figure 6. Characteristic P-V for different radiation values at $T=25^{\circ} \mathrm{C}$. 


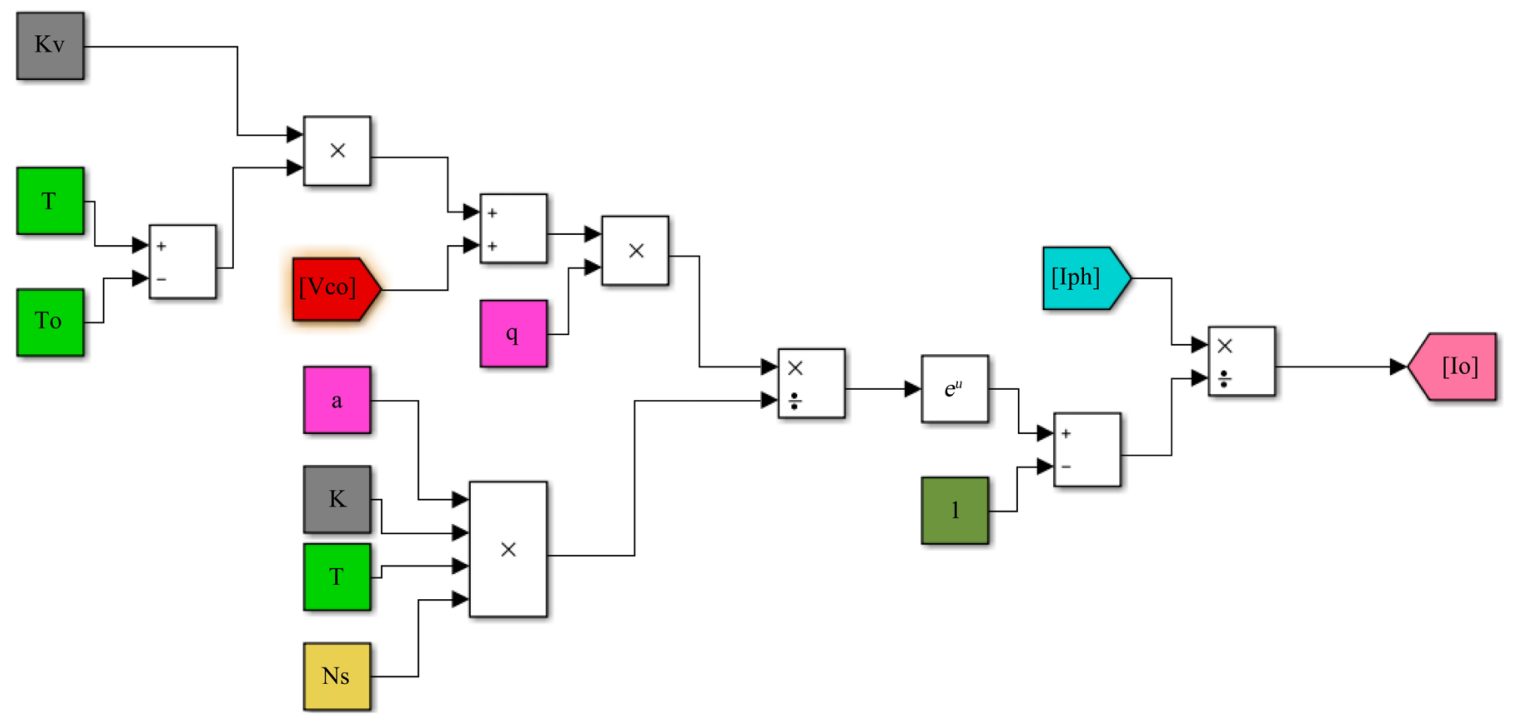

(a)

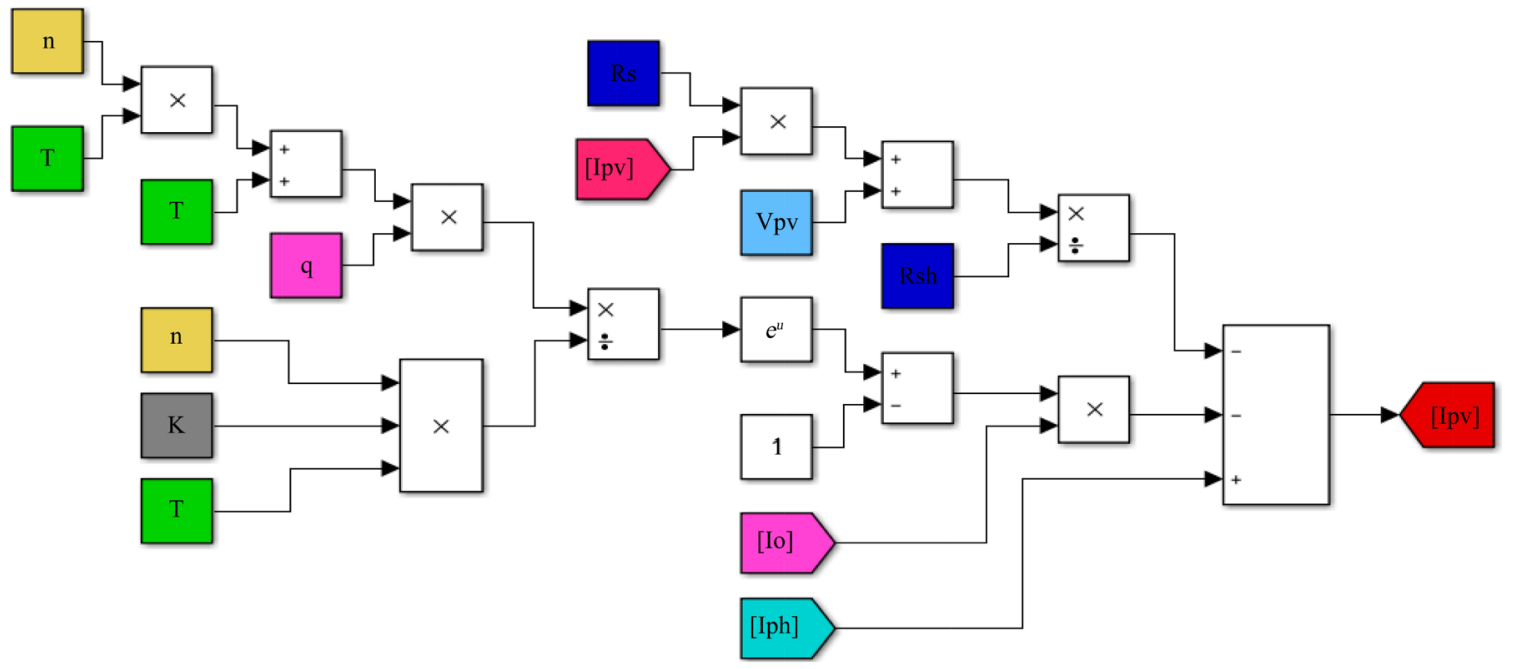

(b)

Figure 7. Sub-block for current calculation. (a) Calculation of current $I_{0}$; (b) Calculation of current $I_{p r}$

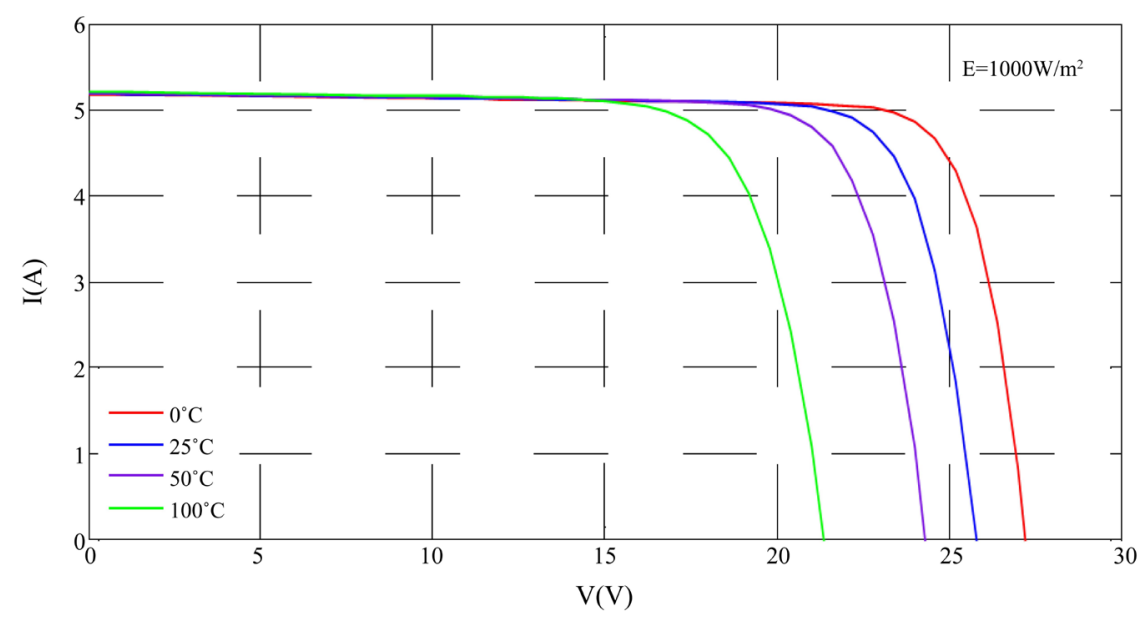

Figure 8. Characteristic I-V for different temperature values at $G=1000 \mathrm{~W} / \mathrm{m}^{2}$. 


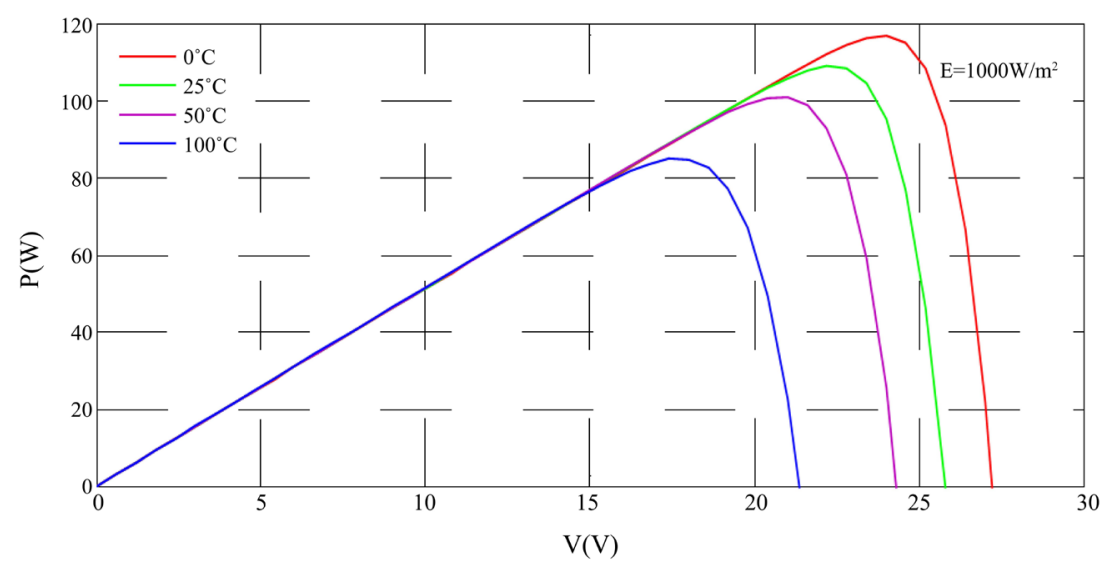

Figure 9. Characteristic P-V for different temperature values at $G=1000 \mathrm{~W} / \mathrm{m}^{2}$.

\subsection{Methods}

\section{MPPT Control via Fuzzy Logic}

Fuzzy logic provides a systematic approach to create the automatic control algorithm by exploiting linguistic variables. In contrast to binary logic, fuzzy variables can ensure a value between 0 and 1 . This command has the advantage of being a robust and relatively simple to build [20]. The general structure of FLC is shown in Figure 10 and consists of three steps: fuzzification, inference and defuzzification.

The purpose of fuzzification is to transform input variables that are initially numerical variables into linguistic variables or scrambled (fuzzy) variables. So we have two input variables, namely the error $E(k)$ and the error variation $\Delta E(k)$ defined by the following equations [6]:

$$
E(k)=\frac{\Delta P_{p v}}{\Delta V_{p v}}
$$

Using Equations (15) and (16) we obtain:

$$
\begin{gathered}
E(k)=\frac{P_{p v}(k)-P_{p v}(k-1)}{V_{p v}(k)-V_{p v}(k-1)} \\
\Delta E(k)=E(k)-E(k-1)
\end{gathered}
$$

Thus its variables will be denoted Negative Big(NB), Negative Small (NS), Null Error (ZE), Positive Small (PS), Positive Big (PB) [21] (Figure 11).

Inference is a step that allows us to define a logical relationship between input $E, \Delta E$ and output $D$. The truth table described in Table 1 will allow us to define the membership rules.

Defuzzification: This step consists in carrying out the inverse operation of fuzzification, i.e. obtaining a numerical value understandable by the external environment (output $D$ ) from a fuzzy definition.

\section{Results and Discussion}

Our fuzzy logic control is developed using the fuzzy toolbox from Matlab/Simulink. 
The inputs of the fuzzy logic controller are $E$ which shows whether the operating point of the load is located to the left or right of the maximum power bridge and $\Delta E$ which shows the direction of the operating point. Their equations are given in (18) and (19). The output of the fuzzy controller $D$ represents the change in the duty cycle of the DC-DC converter. The triangular adhesion functions are chosen for simplicity-they show the fuzzy rule basis created in the current work based on intuitive reasoning and experience. The block diagram for the fuzzy logic controller is shown in Figures 12-14.

Table 1. Interference matrix.

\begin{tabular}{cccccc}
\hline $\mathrm{E} / \Delta \mathrm{E}$ & $\mathrm{NB}$ & $\mathrm{NS}$ & $\mathrm{ZE}$ & $\mathrm{PS}$ & $\mathrm{PB}$ \\
\hline $\mathrm{NB}$ & $\mathrm{ZE}$ & $\mathrm{ZE}$ & $\mathrm{NB}$ & $\mathrm{NB}$ & $\mathrm{NB}$ \\
$\mathrm{NS}$ & $\mathrm{ZE}$ & $\mathrm{ZE}$ & $\mathrm{NS}$ & $\mathrm{NS}$ & $\mathrm{NS}$ \\
$\mathrm{ZE}$ & $\mathrm{NS}$ & $\mathrm{ZE}$ & $\mathrm{ZE}$ & $\mathrm{ZE}$ & $\mathrm{PS}$ \\
$\mathrm{PS}$ & $\mathrm{PS}$ & $\mathrm{PS}$ & $\mathrm{PS}$ & $\mathrm{ZE}$ & $\mathrm{ZE}$ \\
$\mathrm{PB}$ & $\mathrm{PB}$ & $\mathrm{PB}$ & $\mathrm{PB}$ & $\mathrm{ZE}$ & ZE \\
\hline
\end{tabular}

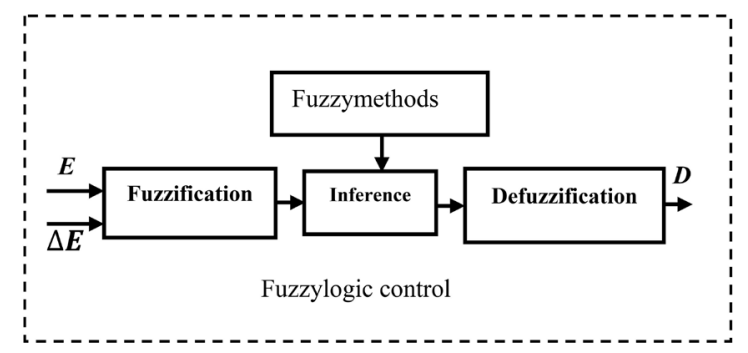

Figure 10. Principle of fuzzy logic control.

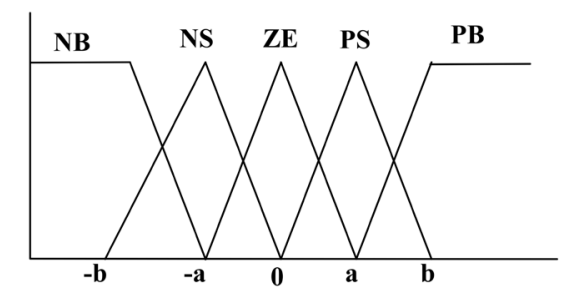

Figure 11. Degree of belonging of the variables.
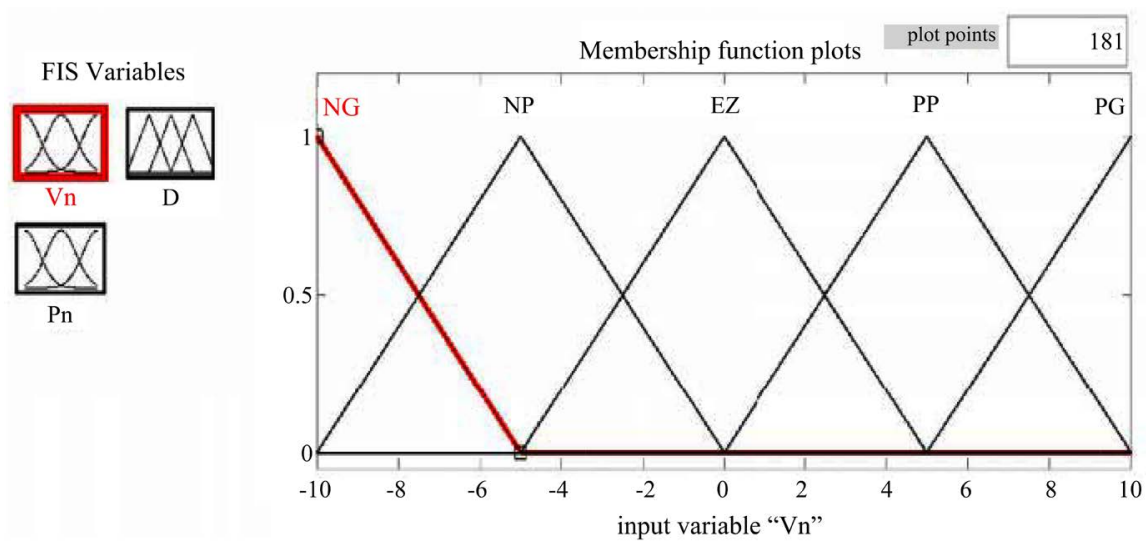

(a) 
FIS Variables
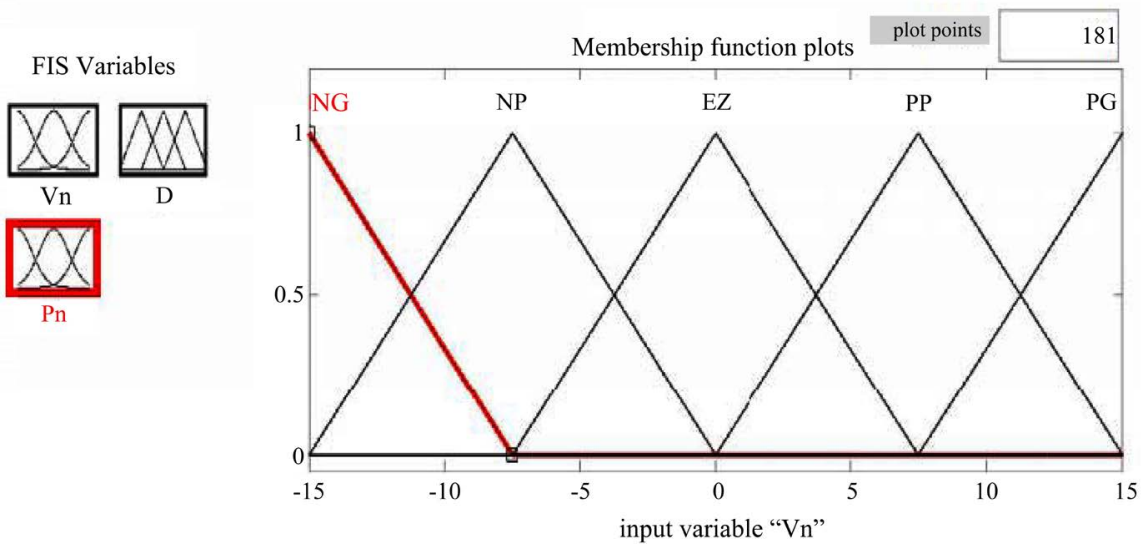

(b)
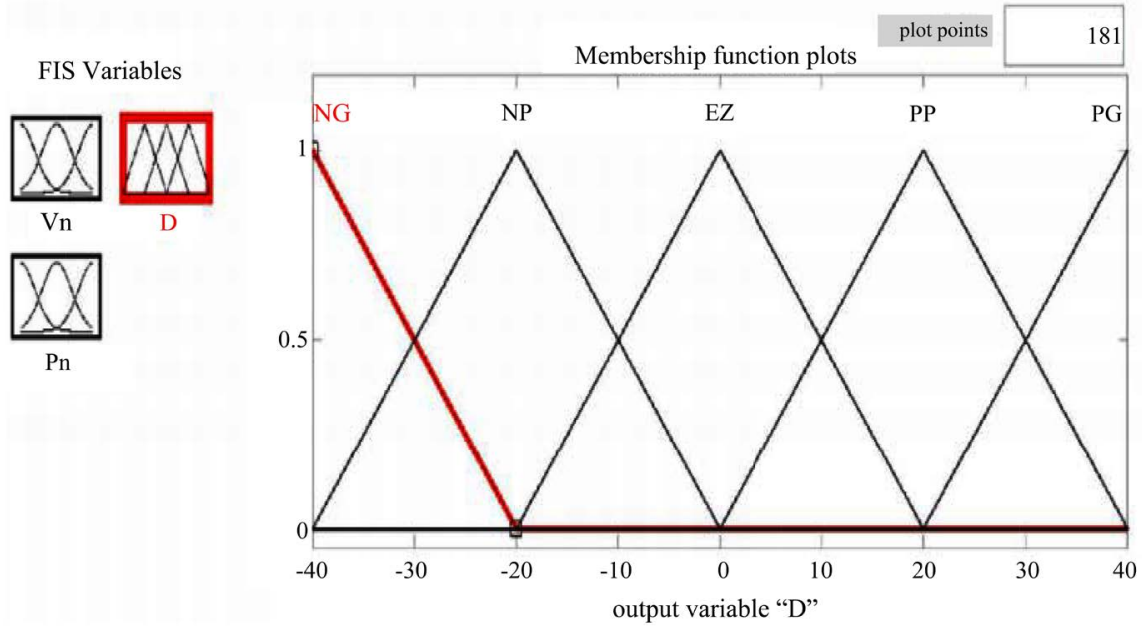

(c)

Figure 12. Fuzzy logic input and output rules. (a) Membership function of the input variable $E$; (b) Membership function of the error variable $\Delta E$; (c) Membership function of the output variable $\Delta D$.

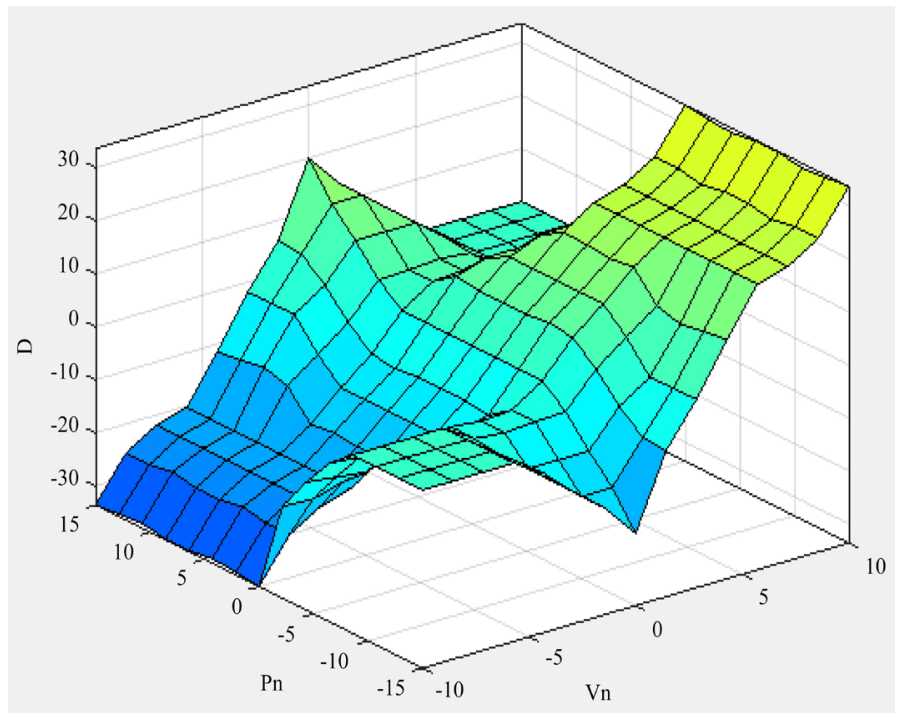

Figure 13. The rules of fuzzy logic on the surface. 


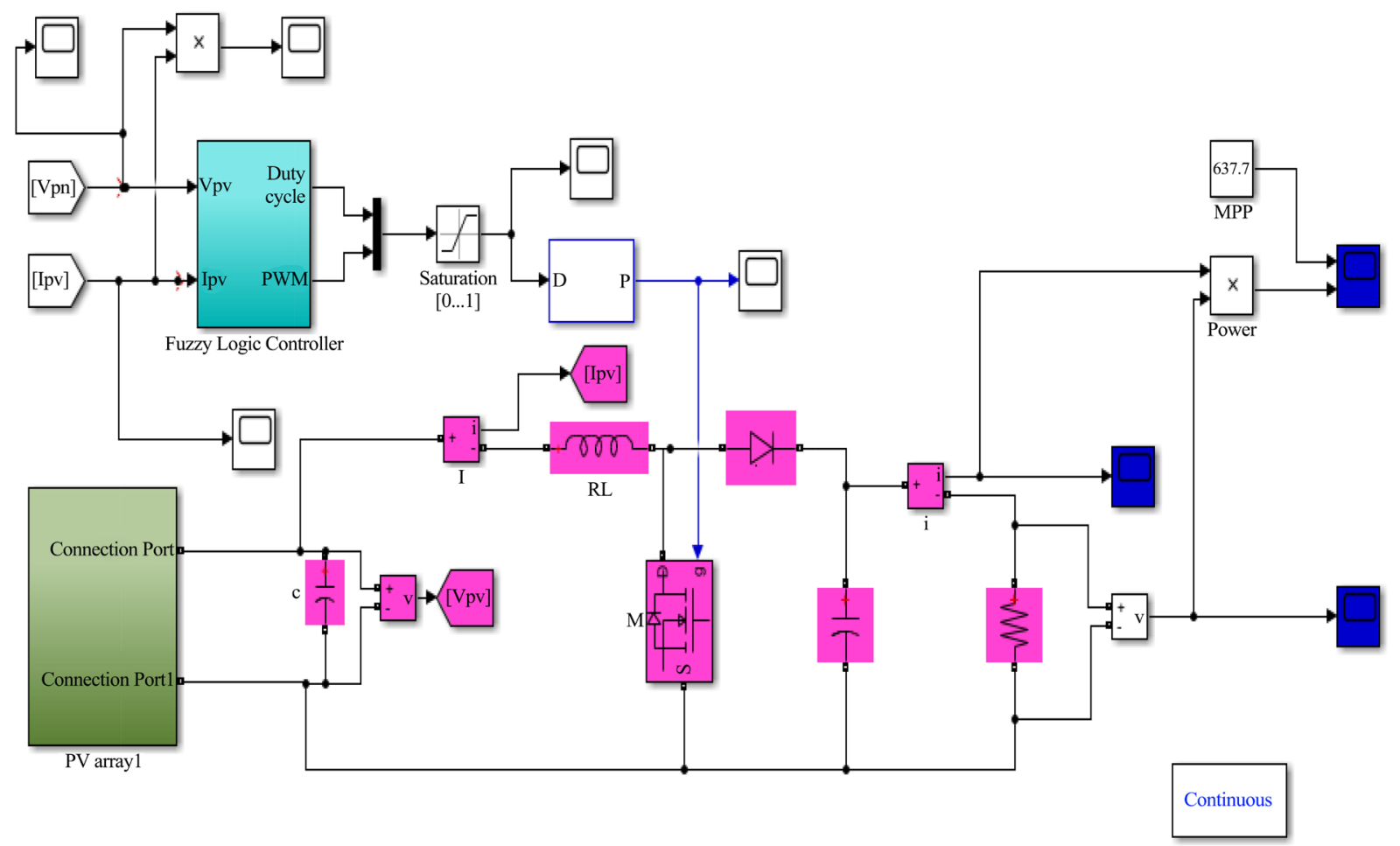

Figure 14. Simulation of the PV system controlled by fuzzy logic.

After the result in Figure 15 allows us to obtain a more stable current. This stability of the current at the maximum operating point is observed from $1.2 \mathrm{~s}$ onwards, whereas the current starts to be stable from $1 \mathrm{~s}$ onwards. While the voltage starts to be stable from $1.2 \mathrm{~s}$ to reach full stability at $1.4 \mathrm{~s}$ (Figure 16). Compared to the P \& O method, we notice that the control by fuzzy logic leads to better performances, with the absence of oscillations in the permanent regimes, and a faster response time. The error is almost non-existent.

After simulating our system with the fuzzy MPPT control, we find that in the case of a disturbance caused by the change in brightness, the system converges to the MPP and remains stable with a minimal ripple rate compared to other types of control. On the other hand, in the case of a disturbance due to the load, the system is insensitive to the disturbance, the power remains stable and does not fluctuate (Figure 17).

\section{Conclusion}

This paper proposed a solution to maintain the power at the maximum operating point regardless of irradiation weather and temperature conditions this, by the good of the MPPT control by fuzzy logic. The simulation results are satisfactory for the reliability of the MPPT control over the PV parameters. The support of the DC/DC converter played an important role regarding the stability of the energy. Furthermore, in anticipation of the integration of distributed generation from renewable sources into the power grid, the grid operator will have to impose special conditions for their connection to guarantee the stability and quality 


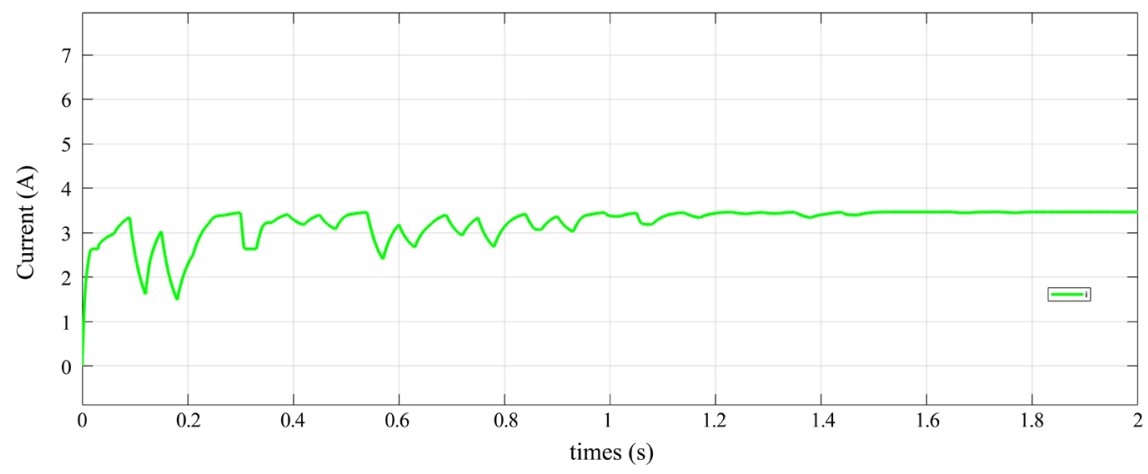

Figure 15. Current pattern facing a load variation.

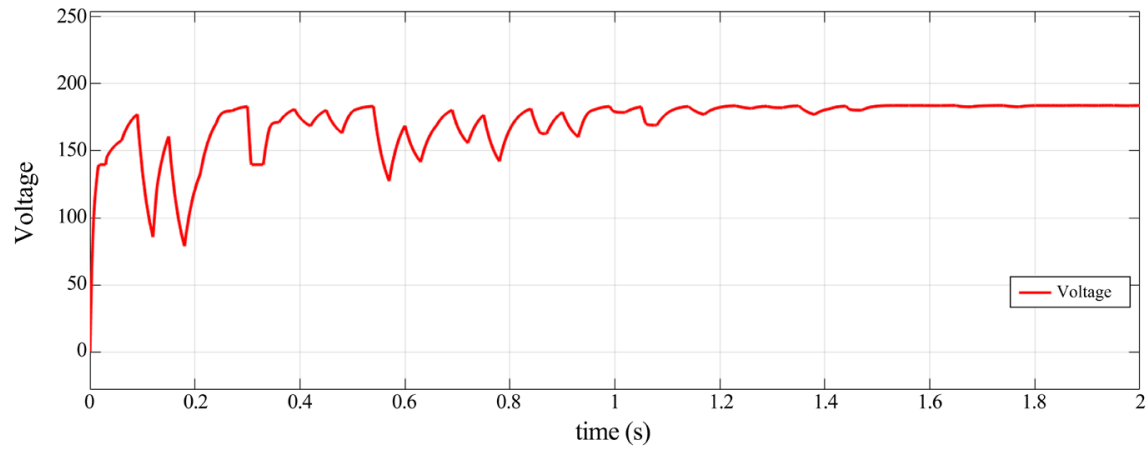

Figure 16. Trend of the voltage in the face of a load variation.

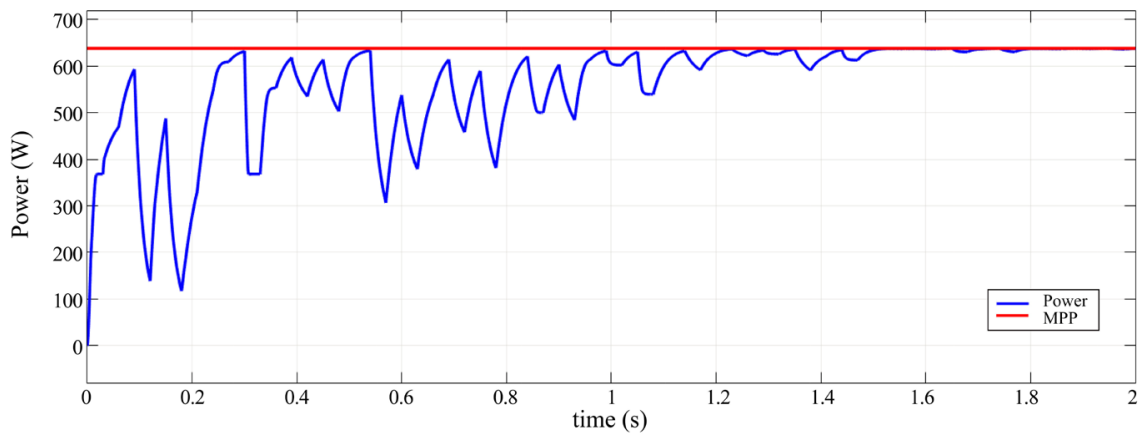

Figure 17. Appearance of the power facing a load variation.

of the grid. Thus, the development of PV in the LV grid may be the most appropriate solution to reduce peak consumption and participate in the grid service. Although these results are interesting, other perspectives can be considered, i.e. the reduction of the harmonic distortion rate by a DCM-controlled boost converter (duty cycle modulation).

\section{Conflicts of Interest}

The authors declare no conflicts of interest regarding the publication of this paper.

\section{References}

[1] Mutoh, N., Ohno, M. and Inoue, T. (2006) A Method for MPPT Control While 
Searching for Parameters Corresponding to Weather Conditions for PV Generation Systems. IEEE Transactions on Industrial Electronics, 53, 1055-1065. https://doi.org/10.1109/TIE.2006.878328

[2] Chomsuwan, K., Prisuwanna, P. and Monyakul, V. (2002) Photovoltaic Grid-Connected Inverter Using Two-Switch Buck-Boost Converter. Conference Record of the 29th IEEE Photovoltaic Specialists Conference, New Orleans, 19-24 May 2002, 1527-1530. https://doi.org/10.1109/PVSC.2002.1190902

[3] Xiao, W.D. and Dunford, W.G. (2004) A Modified Adaptive Hill Climbing MPPT Method for Photovoltaic Power Systems. 2004 IEEE 35th Annual Power Electronics Specialists Conference (IEEE Cat. No. 04CH37551), 3, 1957-1963.

[4] Noguchi, T., Togashi, S. and Nakamoto, R. (2002) Short-Current Pulse-Based Maximum-Power-Point Tracking Method for Multiple Photovoltaic-and-Converter Module System. IEEE Transactions on Industrial Electronics, 49, 217-223. https://doi.org/10.1109/41.982265

[5] Hua, C. and Shen, C. (1998) Comparative Study of Peak Power Tracking Techniques for Solar Storage System. APEC98 13th Annual Applied Power Electronics Conference and Exposition, Anaheim, 15-19 February 1998, 679-685.

[6] Messai, A., Mellit, A., Guessoum, A. and Kalogirou, S.A. (2011) Maximum Power Point Tracking Using a GA Optimized Fuzzy Logic Controller and Its FPGA Implementation. Solar Energy, 85, 265-277.

https://doi.org/10.1016/j.solener.2010.12.004

[7] Patcharaprakiti, N., Premrudeepreechacharn, S. and Sriuthaisiriwong, Y. (2005) Maximum Power Point Tracking Using Adaptive Fuzzy Logic Control for GridConnected Photovoltaic System. Renewable Energy, 30, 1771-1788.

https://doi.org/10.1016/j.renene.2004.11.018

[8] Rakpenthai, C., Uatrongjit, S., Watson, N.R. and Premrudeepreechacharn, S. (2013) On Harmonic State Estimation of Power System with Uncertain Network Parameters. IEEE Transactions on Power System, 28, 4829-4838. https://doi.org/10.1109/TPWRS.2013.2273943

[9] Venkateswari, R. and Sreejith, S. (2019) Factors Influencing the Efficiency of Photovoltaic System. Renewable and Sustainable Energy Reviews, 101, 376-394. https://doi.org/10.1016/j.rser.2018.11.012

[10] Serir, C., Rekioua, D., Mezzai N. andBacha, S. (2016) Supervisor Control and Optimization of Multi-Sources Pumping System with Battery Storage. International Journal of Hydrogen Energy, 41, 20974-20986. https://doi.org/10.1016/j.ijhydene.2016.05.096

[11] Mbarki, B. Farhani, F. and Zaafouri, A. (2019) Comparative Study of Some Maximum Power Point Tracking Algorithms. 2019 International Conference on Signal, Control and Communication (SCC), Hammamet, 16-18 December 2019, 145-149. https://doi.org/10.1109/SCC47175.2019.9116145

[12] Ilyas, A., Khan, M.R. and Ayyub, M. (2020) FPGA Based Real-Time Implementation of Fuzzy Logic Controller for Maximum Power Point Tracking of Solar Photovoltaic System. Optik, 213, Article ID: 164668. https://doi.org/10.1016/j.ijleo.2020.164668

[13] Lim, L.H.I., Ye, Z., Ye, J., Yang, D.Z. and Du, H. (2015) A Linear Method to Extract Diode Model Parameters of Solar Panels from a Single $I$ - $V$ Curve. Renewable Energy, 76, 135-142. https://doi.org/10.1016/j.renene.2014.11.018

[14] Motahhir, S., Ghzizal, A.E. and Derouich, A. (2015) Modélisation et commande d'un panneau photovoltaïque dans l'environnement PSIM. fès, Morocco. 
[15] Huang, C., Wang, L., Yeung, R.S.-C., Zhang, Z.J., Chung, H.S.-H. and Bensoussan, A. (2018) A Prediction Model-Guided Jaya Algorithm for the PV System Maximum Power Point Tracking. IEEE Transactions on Sustainable Energy, 9, 45-55. https://doi.org/10.1109/TSTE.2017.2714705

[16] Jain, A. and Kapoor, A. (2004) Exact Analytical Solutions of the Parameters of Real Solar Cells Using Lambert W-Function. Solar Energy Materials and Solar Cells, 81, 269-277. https://doi.org/10.1016/j.solmat.2003.11.018

[17] Shekoofa, O. and Taherbaneh, M. (2007) Modelling of Silicon Solar Panel by MATLAB/Simulink and Evaluating the Importance of Its Parameters in a Space Application. 2007 3rd International Conference on Recent Advances in Space Technologies, Istanbul, 14-16 June 2007, 719-724. https://doi.org/10.1109/RAST.2007.4284087

[18] Villalva, M.G., Gazoli, J.R. and Filho, E.R. (2009) Comprehensive Approach to Modeling and Simulation of Photovoltaic Arrays. IEEE Transactions on Power Electronics, 24, 1198-1208. https://doi.org/10.1109/TPEL.2009.2013862

[19] Narendra, A., Naik, N.V., Panda, A.K. and Tiwary, N. (2020) A Comprehensive Review of PV Driven Electrical Motors. Solar Energy, 195, 278-303. https://doi.org/10.1016/j.solener.2019.09.078

[20] Verma, P., Garg, R. and Mahajan, P. (2020) Asymmetrical Interval Type-2 Fuzzy Logic Control Based MPPT Tuning for PV System under Partial Shading Condition. ISA Transactions, 100, 251-263. https://doi.org/10.1016/j.isatra.2020.01.009

[21] Salam, Z., Ahmed, J. and Merugu, B.S. (2013) The Application of Soft Computing Methods for MPPT of PV System: A Technological and Status Review. Applied Energy, 107, 135-148. https://doi.org/10.1016/j.apenergy.2013.02.008 